\title{
TOWARDS THE CASE FOR INTRODUCING ENTERPRISE RESOURCE PLANNING AT NATIONAL OIL CORPORATION (NOC) OF LIBYA: A CASE STUDY
}

\author{
Naser Aniba ${ }^{1}$ Jawed Siddiqi $^{2}$ and Mohamed Elmosbahy ${ }^{1}$ \\ ${ }^{1}$ International Marketing Department, National Oil Corporation, Libya \\ ${ }^{2}$ School of Computing, Sheffield Hallam University, UK
}

\begin{abstract}
Enterprise Resource Planning (ERP) systems provide an integrated view of core business processes operating in real-time over the web so it can track its resources, manage its back-office functions and facilitate customer and supplier relationship in an efficient and cost-effective manner that can lead to improved planning and decision quality, and a smoother coordination between business units, resulting in higher efficiency and a quicker response time to customer demands and inquiries. We argue that for the Oil sector the goals to be achieved for a successful ERP deployment are to streamline business processes, compliance with the regulatory environment but at the same time increase profitability This paper aims to contribute to develop a better understanding of the transition required by focusing on objectives, constraints, and the implementation process of ERP in this sector and provide guidelines from lessons learnt. It reports work in progress to share our experiences so that we might benefit from early feedback from those that have already trodden this path as well those that are currently thinking of doing so.
\end{abstract}

\section{KEYWORDS}

NOC, ERP Implementation, Oil Industry

\section{INTRODUCTION}

The oil industry has been for some time a highly volatile and turbulent market, which is difficult to characterise, however some of the key characteristics of complexities involved in managing in a visible and efficient manner are: the enormous levels of investment in equipment and capital, the process of discovering, extracting and delivering oil, the organisational supply chain etc.

For these reasons alone, it is not surprising that Enterprise Resource Planning (ERP) is essential business management software and therefore is frequently present in the sector to effectively manage the day to day operations.

The novelty in the paper is that it sets out the case for introducing an Enterprise Resource Planning (ERP) System at National Oil Corporation (NOC) of Libya.

\section{ERP SYSTEM FOR THE OIL INDUSTRY?}

To develop a sound understanding of the goals to be achieved for a successful ERP implementation a prerequisite is the need to consider the forces that shape the energy sector particularly within the oil industry. Three primary forces shape the oil industry: highly volatile and turbulent markets, a challenging regulatory environment and significant lack of trust from its end customer base. Therefore, the goals to be achieved for a successful deployment are to streamline business processes, compliance with the regulatory environment but at the same time increase profitability.

A key requirement of the oil industry is to accurately and efficiently channel its resources yet comply with the demanding regulations of the extraction industry. An ERP system enable organization to view, understand, process and deliver results via real-time snapshots of the entire operation and therefore focus 
collective insight on issues that are currently trapped in information silos at different levels and structures of the organisation.

Currently company practice is to use hardcopy field ticket methods which are highly prone to be subject to increased costs, can have unknown financial ramifications and certainly lengthy reporting processes. As mentioned previously more recent innovations in ERP systems provide the ability to access live activity updates from the field using mobile devices and real-time reporting and therefore decision making is both better informed and timely

Some specific challenges that an oil company could be facing are: a lack of a consolidated of overview of inventory or assets globally, absence of management of rigs that are constantly changing location as well as their constant need for spare parts and the requirement to automate communication via barcode and mobile devices.

An ERP System, in an oil industry, can lead to:

1. Increased improved visibility of key assets because of gains in the efficiency of key inventory processes and visibility of the entire inventory lifecycle.

2. Enabled the ability to drive efficiencies and increased visibility up and down the supply chain.

3. Leverage automated data collection technology where applicable thereby improving ability to locate inventory at various locations (Warehouse \& Rigs).

4. ERP systems are more secure, all enterprise data is centralized leading to an improved management of globally dispersed resources.

5. Provide the most current and future-proof integration leveraging web services.

\section{NATIONAL OIL CORPORATION LIBYA: A CASE STUDY}

\subsection{An Overview of NOC Libya: Profile, Products and Services}

Libya is a member of the Organization of Petroleum Exporting Countries (OPEC) and holds the largest proven oil reserves in Africa about 46.5 billion barrels $\left(7.38 \times 10^{9} \mathrm{~m}^{3}\right)$ as of 2010 . Oil production was 1.65 million barrels per day $\left(262 \times 10^{3} \mathrm{~m}^{3} / \mathrm{d}\right)$. About $80 \%$ of Libya's proven oil reserves are located in the Sirte Basin Province, which accounts for $90 \%$ of the country's oil output.

The National Oil Corporation (NOC) was established in November 1970 to assume the responsibility for the operation of the oil sector in area of petroleum, supporting the national economy through increasing, developing and exploiting the oil reserves and operating and investing in those reserves to realize optimum returns.

NOC is carrying out exploration and production operation through its own affiliated companies marketing operations of oil and gas, locally and abroad. NOC also has participation agreements with specialized international companies. NOC owns refining, and oil and gas processing companies. NOC also owns national service companies, which carry out oil well drilling and work over operations, provide all drilling material and equipment, lay and maintain oil and gas pipelines, build and maintain oil and gas storage tanks and carry out related technical and economic studies.

\subsection{Enterprise Resource Planning: A Three Step Strategy for NOC Libya}

\subsubsection{Expectations}

To define clear set of expectations it is important to agree the three most important high-level considerations: in-house development or third part buy in, time frame and budget. In relation to first consideration it was important to decide this at the outset as this would have a direct bearing on the latter two. In relation to the latter two reports of variances that have occurred in the past for even modest projects the time frame can typically take $50 \%$ or more than initially estimated whilst the variance can typically exceed three times the initial estimate. These factors will have a direct bearing, but they may well determine the choice in the first consideration. Due to these interdependencies in practice meeting these expectations is an iterative process. 


\subsubsection{Business Requirements}

Before exploring the scope of the business requirements, it was essential to ensure that we had the support of the senior management team to support this venture and as it was initiated by the senior management team this hurdle had been cleared. Furthermore, from the start we were assured that strong motivation would be matched with a strong budget to fulfil the requirements.

In developing a business requirements document for introducing ERP and possibly an ERP "system" the goal here was to provide NOC with an integrated view of its core business activities for all departments so this would provide the visibility for all staff involved in these activates, especially for senior management of all the important processes, across various departments of NOC. In our initial discussions with key stakeholders it became clear that the main functions are, exploration, production, transport, storage, exportation, industrialisation and commercialisation.

For our purposes, we agreed with clients that the main functions of the company could be categorised as:

Onshore and Offshore Drilling Operations: Logistics Management responsible for providing logistics support in terms of transportation of products and equipment.

Technical: Providing technical support to the operations function, field development, maintenance, services and engineering and projects.

Commercialisation: this is essentially Business and Administration support. The former focuses on commercial activities such as marketing procurement, inventory, tendering, finance etc. and the latter includes human resources.

The client wished the primary focus to be on the drilling operations required for exploration on both onshore and offshore areas; this has successfully played an important role in the discovery of oil.

For commercialisation, the client decided that marketing was to be the primary focus. In our conversations, we discovered that the current level of automation is such that most department within these functions are operating either manually or at best using spreadsheets. However, it was important to note that the finance department is attempting to use Oracle and therefore any decisions on our choices had to consider the work and data flows of these and the interoperability of any systems to be recommended with potential implementation that finance might choose.

\subsubsection{ERP Selection}

This requires deciding between the following two options either: a single ERP (vendor selection) or best of breed (selecting the best module for each functional area).

Our initial thoughts favoured the former approach however given that the client has chosen to incorporate ERP in an incremental manner the latter approach seemed more attractive. In fact, at present we have decided to take a hybrid approach in that many ERP vendors are willing to implement functions in an incremental manner. The next question was which vendor to choose potential candidates include SAP and Oracle particularly as these two ERP packages were amongst the most popular choices in that industrial sector and region.

Discussions are currently taking place as to whether to hire a consultant to study the company's requirements and propose a particular ERP system or to carry out the task in-house. As ever there is a trade-off between the options the in-house option has its obvious benefits provided there is sufficient in-house expertise which of course the consultant option offers; however, additional time is required for the tendering process itself could take several months as well as the additional cost.

At present, we are conducting market research to find out the range of costs and timeframe. The initial data collected appeared not very encouraging as the minimum cost identified was USD 8 million (software license, hardware and implementation cost). The average implementation time ranged from 18 months to 3 years; which was beyond the initial estimations, as the company was aiming to complete the transition in 12 months. However, our decision to proceed incrementally means that these figures are not representative, and we will be able to control the time frame and budgets in an incremental manner. 


\section{CONCLUSIONS}

In conclusion, in presenting work in progress we are looking to share our experience so that we might benefit from early feedback from those that have already trodden this path as well those that are currently thinking of doing so. Additionally, we are seeking potential partners from the vendor community to provide initial guidance and outline proposals of what they have to offer.

\section{REFERENCES}

Ceylon Petroleum Storage Terminals Limited has decided to implement SAP. Available online at: http://www.cpstl.lk/sap.html accessed on 05.12.2018.

Chang, M. K., Cheung, W., Yeung, J. H. Y. (2008) Understanding ERP System Adoption from the User's Perspective, International Journal of Production Economics, vol. 113(2), 928-942.

Kimberling, E. Lessons Learned From Oil and Gas ERP Implementations August 13, 2014 .Available online at: http://panorama-consulting.com/lessons-learned-from-oil-and-gas-erp-implementations/. Accessed on 05.12.2018.

Laughlin, S.P. (1999) An ERP game plan, Journal of Business Strategy, 20(1), 32-37.

Mendelson, H. (1999) ERP Overview: Stanford Business School, Mimeo (1999).

Mishra, A. and Mishra, D. (2009) ERP System Implementation: An Oil and Gas Exploration Sector Perspective, F. Bomarius et al. (Eds.): PROFES 2009, LNBIP 32, 416-428.

Mishra, A. and Mishra, D. (2011). ERP project implementation: evidence from the oil and gas sector. Acta Polytechnica Hungarica, 8(4), 55-74.

Srivastava, M. and Gips, B.J. (2009) Chinese cultural implications for ERP implementation. Journal of technology management \&amp; innovation, 4(1), pp. 105-113. 